\title{
Matéria orgânica de horizontes superficiais em topolitossequências em ambiente de Mar de Morros, Pinheiral, $\mathbf{R J}^{1}$
}

\author{
Organic matter of surface horizons in topolito-sequences from an environment in Mar \\ de Morros, Pinheiral, Rio de Janeiro, Brazil
}

\author{
Ademir Fontana ${ }^{2 *}$, Marcos Gervasio Pereira ${ }^{3}$, Lúcia Helena Cunha dos Anjos ${ }^{3}$, Adailde Carmo dos $\operatorname{Santos}^{4}$ e \\ Thiago Andrade Bernini ${ }^{5}$
}

\begin{abstract}
RESUMO - O objetivo deste trabalho foi quantificar o carbono orgânico e as frações húmicas de horizontes superficiais de perfis de solo em três topolitossequências no ambiente de Mar de Morros, no município de Pinheiral, RJ. Foram selecionadas as topolitossequências: T1 (basalto), T2 (muscovita-biotita-gnaisse) e T3 (gabro). Os horizontes superficiais de 14 perfis de solo, sob cobertura de pastagem (T1 e T3) e pastagem mista não manejada e leguminosa (pasto sujo/capoeira) (T2), foram descritos e coletados para análises químicas, físicas e do teor de carbono nas frações húmicas. Os teores de carbono orgânico variaram de acordo com o material de origem e decrescem na seguinte ordem: T3 > T1 > T2. Os teores de carbono orgânico aumentam do topo para a várzea na T1, ocorrendo o inverso na T3 e sem um padrão definido na T2. A fração humina predominou em todos os perfis de solo das topolitossequências e foi seguida pela fração ácidos fúlvicos na T1 e de forma equitativa entre as frações ácidos fúlvicos e ácidos húmicos na T2 e T3. Considerando o ambiente similar em termos da vegetação original e o uso agrícola, as mudanças no carbono do solo e nas frações húmicas podem refletir as interações com os componentes minerais e processos pedogenéticos, influenciados pelo material de origem e o relevo.
\end{abstract}

Palavras-chave: Pedogênese. Frações húmicas. Atributos edáficos.

\begin{abstract}
The aim of this study was to quantify the organic carbon and humic fractions of the surface horizons of soil profiles in three topolito-sequences from the Mar de Morros environment in the town of Pinheiral, in the state of Rio de Janeiro, Brazil. The topolito-sequences selected were: T1 (basalt), T2 (muscovite-biotite-gneiss), and T3 (gabbro). The surface horizons of 14 soil profiles under pasture (T1 and T3), and unmanaged mixed pasture and leguminous plants (shrub/vegetation) (T2), were marked out and collected for chemical and physical analysis, and evaluation of the carbon content of the humic fractions. The organic-carbon content varied according to the source material, decreasing in the order: $\mathrm{T} 3>\mathrm{T} 1>\mathrm{T} 2$. The organic-carbon content increased from the highest point to the lowlands in $\mathrm{T} 1$, with the opposite occurring in $\mathrm{T} 3$, and no definite pattern being seen in $\mathrm{T} 2$. The humin fraction predominated in all the topolito-sequence soil profiles, being followed by the fulvic acid fraction in T1, and by the fulvic and humic acid fractions equally in T2 and T3. Considering the environments as being similar in terms of original vegetation and agricultural use, changes in the carbon and humic fractions of the soil may reflect interactions with mineral components and pedogenic processes, influenced by the original material and the landscape.
\end{abstract}

Key words: Pedogenesis. Humic fractions. Edaphic attributes.

\footnotetext{
*Autor para correspondência

Recebido para publicação em 10/09/2012; aprovado 03/12/2013

Parte da Tese de Doutorado do quarto autor apresentada ao Curso de Pós-Graduação em Agronomia, Ciência do Solo da Universidade Federal Rural do Rio de Janeiro, Projeto apoiado pelo Conselho Nacional de Desenvolvimento Científico e Tecnológico/CNPq

${ }^{2}$ Embrapa Solos, Rio de Janeiro-RJ, Brasil, 22.460-000, ademir.fontana@embrapa.br

${ }_{3}^{3}$ Departamento de Solos, Universidade Federal Rural do Rio de Janeiro, Seropédica-RJ, Brasil, 23.890-000, gervasio@ufrrj.br, lanjos@ufrrj.br ${ }^{4}$ Instituto Federal de Educação, Ciência e Tecnologia da Bahia, Campus Valença, Valença-BA, Brasil, 44.380-000, adacsantos@gmail.com ${ }^{5}$ Instituto Federal de Educação, Ciência e Tecnologia do Rio de Janeiro, Campus Pinheiral, Pinheiral-RJ, Brasil, 27.197-000, thiagoagronomo@ ibest.com.br
} 


\section{INTRODUÇÃO}

$\mathrm{O}$ estoque de carbono original dos solos é controlado pelo clima, paisagem, vegetação, mineralogia e pelas interações entre esses fatores (TORNQUIST et al., 2009). Também, a quantidade e qualidade da matéria orgânica do solo (MOS) são governadas pela drenagem, acidez, disponibilidade de nutrientes, composição da microbiota e da mesofauna, temperatura do solo, relação carbono/nitrogênio e conteúdo de lignina do material vegetal, além dos distúrbios ocasionados pelo cultivo, teor e tipo de argila do solo (GREENLAND et al., 1992).

Nas regiões tropicais, quando a vegetação nativa é substituída por sistemas agrícolas, o estoque de MOS pode reduzir significativamente pela exposição da matéria orgânica a uma intensa atividade microbiológica, o que resulta na sua rápida decomposição e mineralização (MIELNICZUK et al., 2003). Nos sistemas agrícolas, a dinâmica da MOS pode ser modificada pelo manejo, por meio da seleção de culturas e formas de preparo do solo e, pela adição de fertilizantes minerais e materiais orgânicos (LEITE et al., 2003).

Ademais, associados aos fatores apresentados anteriormente, somam-se aqueles relacionados principalmente à preservação da matéria orgânica, como a recalcitrância intrínseca dos componentes orgânicos, a oclusão física e a proteção química por interação com a superfície dos minerais e as variações ambientais (WANDER, 2004).

Diante disto, os estudos que visam melhorar a compreensão da dinâmica da MOS em áreas de cultivo e de cobertura natural não ficam restritos à avaliação dos teores de carbono orgânico e, desta forma, buscam estudar os compartimentos da MOS (SOUZA et al., 2006). Uma forma mais específica de analisar a capacidade que os solos têm de acumular matéria orgânica está relacionada à distribuição das frações húmicas, na qual é possível correlacionar a mobilidade e/ou estabilização do material orgânico (FONTANA et al., 2010).

A distribuição das frações húmicas pode ser influenciada pela variação do material de origem sendo que este pode estar associado ao relevo. Esta correlação pode ser observada no trabalho de Pereira et al. (2013) em solos de uma topossequência sobre calcário na Serra da Boboquena (MS), no qual os autores observaram baixos valores da relação frações alcalinosolúveis/fração humina nos horizontes superficiais. Em transectos na região dos Lagos (RJ), Ibraimo et al. (2004) verificaram equilíbrio entre a fração humina e as alcalino solúveis nos solos desenvolvidos sobre biotita-gnaisse e o predomínio das frações alcalino solúveis em detrimento a humina nos sedimentos orgânicos.
Com intuito de avaliar como as variações do relevo e do material de origem influenciam a matéria orgânica do solo, foi quantificado o teor de carbono orgânico e as frações húmicas em horizontes superficiais de perfis de solo em três topolitossequências no ambiente de Mar de Morros, município de Pinheiral, RJ.

\section{MATERIAL E MÉTODOS}

\section{Localização e meio físico da área de estudo}

A área de estudo está localizada na microbacia do Ribeirão Cachimbal, na região do Médio Vale do Paraíba do Sul, município de Pinheiral, RJ. Foram selecionadas três topolitossequências (T1, T2 e T3) em diferentes materiais de origem (Tabela 1): T1: rocha ígnea extrusiva básica (basalto), T2: rocha metamórfica ácida (muscovitabiotita-gnaisse) e T3: rocha intrusiva básica (gabro). A cobertura vegetal atual da T1 e T3 é de pastagem (Brachiaria) e na T2 pastagem mista não manejada e leguminosa (pasto sujo/capoeira) (SANTOS, 2009).

O relevo da microbacia é acidentado (forte ondulado) e característico da feição geomorfológica "Mar de Morros", com a formação de diversos vales estruturais que conformam uma rede de drenagem diversificada (BRASIL, 1983). A cobertura vegetal original é de Floresta Pluvial Baixo Montana, parte da Mata Atlântica. O clima é definido como Cwa, com inverno seco e verão chuvoso, a precipitação pluvial anual está em torno de $1.308 \mathrm{~mm}$ e a temperatura média anual é de $20,9^{\circ} \mathrm{C}$ (BRASIL, 1983).

\section{Amostragem e caracterização dos solos}

Foram tomadas amostras de horizontes superficiais (A e $\mathrm{AB}$ ) em trincheiras abertas em diferentes posições nas topolitossequências (Tabela 1). Os perfis de solo foram descritos e coletados segundo Santos et al. (2005). Após a coleta as amostras foram secadas ao ar, destorroadas e peneiradas a $2 \mathrm{~mm}$ de malha, obtendo-se a terra fina seca ao ar (TFSA).

Na TFSA foi quantificado o carbono orgânico (C org), com a oxidação da matéria orgânica pelo dicromato de potássio $0,2 \mathrm{~mol} \mathrm{~L}^{-1} \mathrm{em}$ meio ácido (ácido sulfúrico) e titulação com o sulfato ferroso amoniacal 0,1 mol L-1. $\mathrm{O} \mathrm{pH}$ (água) foi determinado na suspensão TFSAsolução de 1:2,5 (água e $\mathrm{KCl} 1 \mathrm{~mol} \mathrm{~L}^{-1}$ ) e com leitura feita em potenciômetro. Os cátions trocáveis $\left(\mathrm{Ca}^{2+}+\right.$ $\mathrm{Mg}^{2+}, \mathrm{Al}^{3+}$ ) foram extraídos com solução de $\mathrm{KCl} 1 \mathrm{~mol} \mathrm{~L}^{-1}$ na proporção TFSA-solução de 1:10, sendo obtido o $\mathrm{Ca}^{2+}+$ $\mathrm{Mg}^{2+}$ e o $\mathrm{Ca}^{2+}$ por complexometria. $\mathrm{O} \mathrm{Mg}^{2+}$ foi obtido por diferença do $\mathrm{Ca}^{2+}+\mathrm{Mg}^{2+}$ e o $\mathrm{Ca}^{2+}$. $\mathrm{O} \mathrm{Al}^{3+}$ foi determinado por titulação. Sódio e potássio trocáveis $\left(\mathrm{Na}^{+}+\mathrm{K}^{+}\right)$ foram extraídos com solução de $\mathrm{HCl} 0,05 \mathrm{~mol} \mathrm{~L}^{-1} \mathrm{e}_{2} \mathrm{SO}_{4}$ 
Tabela 1 - Classificação dos solos e caracterização geral das topolitossequências

\begin{tabular}{|c|c|c|c|c|c|}
\hline \multirow{2}{*}{ Topo/Perfil ${ }^{(1)}$} & \multirow{2}{*}{ Classe de Solo - SiBCS ${ }^{(2)}$} & \multirow{2}{*}{$\frac{\text { Elevação }}{\mathrm{m}}$} & \multirow{2}{*}{$\frac{\text { Declividade }}{\%}$} & \multirow{2}{*}{ Posição } & \multirow{2}{*}{ Forma da Encosta } \\
\hline & & & & & \\
\hline T1P1 & Nitossolo Háplico & 462 & 16 & Topo & Plana \\
\hline $\mathrm{T} 1 \mathrm{P} 2$ & Latossolo Vermelho-Amarelo & 452 & 38 & Terço Superior & Convexa \\
\hline $\mathrm{T} 1 \mathrm{P} 2$ & Latossolo Vermelho-Amarelo & 452 & 38 & Terço Superior & Convexa \\
\hline T1P3 & Latossolo Vermelho-Amarelo & 431 & 50 & Terço Médio & Convexa \\
\hline $\mathrm{T} 1 \mathrm{P} 4$ & Latossolo Vermelho-Amarelo & 402 & 23 & Terço Inferior & Côncava \\
\hline $\mathrm{T} 1 \mathrm{P} 4$ & Latossolo Vermelho-Amarelo & 402 & 23 & Terço Inferior & Côncava \\
\hline T1P5 & Gleissolo Háplico & 385 & - & Várzea & Plana \\
\hline $\mathrm{T} 2 \mathrm{P} 1$ & Cambissolo Háplico & 417 & 7 & Topo & Plana \\
\hline $\mathrm{T} 2 \mathrm{P} 1$ & Cambissolo Háplico & 417 & 7 & Topo & Plana \\
\hline $\mathrm{T} 2 \mathrm{P} 2$ & Argissolo Vermelho-Amarelo & 415 & 8 & Terço Superior & Convexa \\
\hline $\mathrm{T} 2 \mathrm{P} 2$ & Argissolo Vermelho-Amarelo & 415 & 8 & Terço Superior & Convexa \\
\hline $\mathrm{T} 2 \mathrm{P} 3$ & Cambissolo Háplico & 411 & 116 & Terço Médio & Retilínea \\
\hline $\mathrm{T} 2 \mathrm{P} 4$ & Argissolo Amarelo & 378 & 16 & Terço Inferior & Côncava \\
\hline $\mathrm{T} 2 \mathrm{P} 4$ & Argissolo Amarelo & 378 & 16 & Terço Inferior & Côncava \\
\hline $\mathrm{T} 2 \mathrm{P} 5$ & Gleissolo Háplico & 372 & - & Várzea & Plana \\
\hline $\mathrm{T} 3 \mathrm{P} 1$ & Nessolo Regolítico & 447 & 28 & Topo & Plana \\
\hline $\mathrm{T} 3 \mathrm{P} 1$ & Nessolo Regolítico & 447 & 28 & Topo & Plana \\
\hline $\mathrm{T} 3 \mathrm{P} 2$ & Chernossolo Argilúvico & 430 & 42 & Terço Superior & Convexa \\
\hline T3P3 & Chernossolo Argilúvico & 413 & 43 & Terço Médio & Convexa \\
\hline T3P4 & Chernossolo Argilúvico & 390 & - & Terço Inferior & Convexa \\
\hline
\end{tabular}

${ }^{(1)}$ Topo: topossequência; ${ }^{(2)}$ SiBCS: Sistema Brasileiro de Classificação de Solos (Embrapa, 2006)

0,0125 mol L ${ }^{-1}$ na proporção TFSA-solução de 1:10 e determinados por fotometria de chama. A acidez extraível $\left(\mathrm{H}^{+}+\mathrm{Al}^{3+}\right)$ foi obtida pela extração com solução de acetato de cálcio $1 \mathrm{~mol} \mathrm{~L}^{-1}(\mathrm{pH} 7,0)$ na proporção TFSA-solução de 1:15 e determinada por titulação. $\mathrm{O} \mathrm{H}^{+}$obtido por diferença entre o valor de acidez extraível e o $\mathrm{Al}^{3+}$. A soma de bases trocáveis (SB) foi obtida pela soma dos valores de $\mathrm{Ca}^{2+}+\mathrm{Mg}^{2+}+\mathrm{Na}^{+}+\mathrm{K}^{+}$e a capacidade de troca catiônica a pH 7,0 (CTC) determinada pela soma da SB $+\left(\mathrm{H}^{+}+\mathrm{Al}^{+3}\right)$. A composição granulométrica, obtida pela dispersão da TFSA com $\mathrm{NaOH} 1 \mathrm{~mol} \mathrm{~L}^{-1}$ e agitação em baixa rotação por 16 horas, sendo o teor de argila total determinado pelo método da pipeta. As frações da areia foram separadas em areia grossa $(2-0,210 \mathrm{~mm})$ e areia fina $(0,210-0,053 \mathrm{~mm})$. O silte foi obtido por diferença (EMBRAPA, 1997).

As frações húmicas: fração ácidos fúlvicos (CFAF), fração ácidos húmicos (C-FAH) e fração humina
(C-HUM) foram obtidas pela técnica de solubilidade diferencial, conforme proposta de Benites et al. (2003). Na extração das frações húmicas foi utilizado $1,0 \mathrm{~g}$ de TFSA, submetida ao contato com $20 \mathrm{~mL}$ de solução de hidróxido de sódio $0,1 \mathrm{~mol} \mathrm{~L}^{-1}$ e centrifugado a $5.000 \mathrm{~g}$ por 30 minutos, com repetição desta etapa uma vez. $\mathrm{O}$ extrato alcalino obtido $(40 \mathrm{~mL})$ teve o pH ajustado a 1,0 com solução de ácido sulfúrico $20 \%$, seguido de decantação por 18 horas em geladeira e o resíduo seco a $65^{\circ} \mathrm{C}$. Do extrato alcalino, o precipitado (fração ácidos húmicos) foi separado da fração solúvel (fração ácidos fúlvicos) por filtragem e ambos os volumes aferidos a $50 \mathrm{~mL}$ com água destilada.

A determinação do carbono orgânico nas frações ácidos fúlvicos e húmicos foi feita por oxidação com dicromato de potássio $0,042 \mathrm{~mol} \mathrm{~L}^{-1}$ e de ácido sulfúrico concentrado aquecido a $150{ }^{\circ} \mathrm{C}$ e, titulação com sulfato ferroso amoniacal $0,0125 \mathrm{~mol} \mathrm{~L}^{-1} \mathrm{e}$ indicador ferroin. No resíduo seco em estufa, foi determinado o carbono 
orgânico na fração humina com adição de dicromato de potássio $0,1667 \mathrm{~mol} \mathrm{~L}^{-1}$ e ácido sulfúrico concentrado e aquecido a $150{ }^{\circ} \mathrm{C}$, seguida por titulação com sulfato ferroso amoniacal $0,25 \mathrm{~mol} \mathrm{\textrm {L } ^ { - 1 }} \mathrm{e}$ indicador ferroin (YEOMANS; BREMNER, 1988).

\section{RESULTADOS E DISCUSSÃO}

A classificação taxonômica dos perfis de solo em cada topolitossequência indica a ocorrência de horizonte diagnóstico superficial A chernozêmico em T3P3, T3P3 e T3P4, ou seja, horizonte com alta saturação por bases, espesso e de cor escura. Os demais perfis têm horizonte superficial A moderado (EMBRAPA, 2006) (Tabela 1).

Os teores de argila apresentaram a seguinte ordenação decrescente: T1 > T3 > T2 (Tabela 2). Na T1 os teores de argila dos horizontes foram sempre superiores a $450 \mathrm{~g} \mathrm{~kg}^{-1}$, sendo exceção o T1P5, localizado na parte mais baixa, e com o menor valor $\left(250 \mathrm{~g} \mathrm{~kg}^{-1}\right)$. Para a T3, os teores de argila estão entre 291 e $364 \mathrm{~g} \mathrm{~kg}^{-1}$, enquanto na T2, observa-se a menor participação da fração argila, com teores entre 190 e $254 \mathrm{~g} \mathrm{~kg}^{-1}$.

Para o complexo sortivo, observa-se o predomínio dos cátions trocáveis $\left(\mathrm{Ca}^{2+}+\mathrm{Mg}^{2+}\right)$ e a CTC, seguindo a ordem decrescente $\mathrm{T} 3>\mathrm{T} 1>\mathrm{T} 2$ e ainda destacando os baixos teores de $\mathrm{Al}^{3+}$ (Tabela 2). Os menores valores de $\mathrm{Ca}^{2+}+\mathrm{Mg}^{2+}$ na T3 foram quantificados no terço inferior e o máximo no topo da encosta (11,7 a 21,4 $\left.\mathrm{cmol}_{\mathrm{c}} \mathrm{kg}^{-1}\right)$. Para a T1 os maiores valores ocorreram no terço inferior e na várzea e o menor no terço superior da encosta (1,9 a $9,0 \mathrm{cmol}_{\mathrm{c}} \mathrm{kg}^{-1}$ ). Para a T2 verificou-se o mesmo padrão observado para a T1 com o menor valor observado na parte mais baixa e o maior no topo da encosta $(2,5$ a $\left.8,2 \mathrm{cmol}_{\mathrm{c}} \mathrm{kg}^{-1}\right)$.

Tabela 2 - Atributos físicos e químicos dos horizontes superficiais nas topolitossequências

\begin{tabular}{|c|c|c|c|c|c|c|c|c|}
\hline \multirow{2}{*}{ Topo/Perfil $^{(1)}$} & \multirow{2}{*}{ Horizonte } & \multirow{2}{*}{ Posição } & \multirow{2}{*}{$\frac{\text { Argila }}{\mathrm{g} \mathrm{kg}^{-1}}$} & \multirow{2}{*}{$\frac{\mathrm{pH}}{\text { água }}$} & $\mathrm{Ca}^{2+}+\mathrm{Mg}^{2+}$ & $\mathrm{SB}^{(2)}$ & $\mathrm{Al}^{3+}$ & $\mathrm{CTC}^{(3)}$ \\
\hline & & & & & \multicolumn{4}{|c|}{ - } \\
\hline T1P1 & Ap & Topo & 518 & 5,2 & 4,8 & 5,0 & 0,3 & 11,2 \\
\hline $\mathrm{T} 1 \mathrm{P} 2$ & Ap & Terço Superior & 585 & 4,7 & 2,9 & 3,1 & 0,5 & 10,3 \\
\hline $\mathrm{T} 1 \mathrm{P} 2$ & $\mathrm{AB}$ & Terço Superior & 612 & 4,8 & 1,9 & 2,0 & 0,8 & 8,8 \\
\hline T1P3 & Ap & Terço Médio & 596 & 5,2 & 4,0 & 4,2 & 0,2 & 11,0 \\
\hline T1P4 & Ap & Terço Inferior & 453 & 6,6 & 9,0 & 9,1 & 0,1 & 11,9 \\
\hline T1P4 & $\mathrm{AB}$ & Terço Inferior & 545 & 6,5 & 7,9 & 8,0 & 0,1 & 11,3 \\
\hline T1P5 & Ap & Várzea & 250 & 5,1 & 6,1 & 6,6 & 0,1 & 17,2 \\
\hline $\mathrm{T} 2 \mathrm{P} 1$ & Ap1 & Topo & 235 & 5,9 & 8,2 & 8,5 & 0,1 & 12,8 \\
\hline $\mathrm{T} 2 \mathrm{P} 1$ & Ap2 & Topo & 211 & 5,8 & 4,6 & 4,8 & 0,1 & 8,2 \\
\hline $\mathrm{T} 2 \mathrm{P} 2$ & Ap1 & Terço Superior & 251 & 5,6 & 4,2 & 4,5 & 0,1 & 8,1 \\
\hline $\mathrm{T} 2 \mathrm{P} 2$ & Ap2 & Terço Superior & 244 & 5,4 & 2,5 & 2,7 & 0,2 & 6,2 \\
\hline $\mathrm{T} 2 \mathrm{P} 3$ & Ap & Terço Médio & 254 & 5,5 & 3,3 & 3,5 & 0,1 & 7,8 \\
\hline $\mathrm{T} 2 \mathrm{P} 4$ & Ap & Terço Inferior & 207 & 5,8 & 4,2 & 4,5 & 0,1 & 7,6 \\
\hline $\mathrm{T} 2 \mathrm{P} 4$ & $\mathrm{AB}$ & Terço Inferior & 217 & 5,6 & 2,9 & 2,8 & 0,5 & 5,2 \\
\hline $\mathrm{T} 2 \mathrm{P} 5$ & Ap & Várzea & 190 & 5,5 & 4,0 & 4,3 & 0,4 & 9,6 \\
\hline T3P1 & Ap1 & Topo & 364 & 6,5 & 21,4 & 21,8 & 0,0 & 22,9 \\
\hline T3P1 & Ap2 & Topo & 342 & 6,6 & 18,5 & 18,7 & 0,0 & 19,3 \\
\hline T3P2 & $\mathrm{Ap}$ & Terço Superior & 314 & 6,4 & 16,4 & 16,6 & 0,0 & 18,3 \\
\hline T3P3 & Ap & Terço Médio & 340 & 6,6 & 14,6 & 14,7 & 0,0 & 15,7 \\
\hline T3P4 & Ap & Terço Inferior & 291 & 6,8 & 11,7 & 12,1 & 0,0 & 12,4 \\
\hline
\end{tabular}

${ }^{(1)}$ Topo: topossequência; ${ }^{(2)} \mathrm{SB}$ : soma de bases; ${ }^{(3)} \mathrm{CTC}$ : capacidade de troca catiônica a pH 7,0 
A variação da composição granulométrica e do complexo sortivo é indicativa da variação do material de origem entre as topolitossequências, de rochas básicas (T1 - basalto e T3 - gabro) e ácida (T2 - muscovitabiotita-gnaisse), bem como da posição na paisagem, associado à forma e à declividade da encosta.

Quanto aos teores de carbono orgânico ( $\mathrm{C}$ org), verificou-se a distribuição $\mathrm{T} 3>\mathrm{T} 1>\mathrm{T} 2$, com teores variando entre 8,2 e 40,0 $\mathrm{g} \mathrm{kg}^{-1}$, nos T2P4 e T3P1, respectivamente (Tabela 3 ). Os teores de $\mathrm{C}$ org aumentam do topo da encosta em direção à várzea, do T1P1 a T1P5 (18,9 a 36,8 $\mathrm{g} \mathrm{kg}^{-1}$ ), enquanto que em T3 observa-se padrão inverso, sendo o máximo teor no T3P1 $\left(40,0 \mathrm{~g} \mathrm{~kg}^{-1}\right)$ e o mínimo no T3P4 (14,9 $\left.\mathrm{g} \mathrm{kg}^{-1}\right)$. Para T2, o topo apresenta o teor máximo $\left(31,7 \mathrm{~g} \mathrm{~kg}^{-1}\right)$ e o teor mínimo nas posições intermediárias da paisagem (terço médio e inferior)

Os teores de $\mathrm{C}$ org de solos desenvolvidos a partir das rochas básicas (T3 e T1) tendem a ser superiores em comparação àqueles formados por rochas ácidas (T2). A composição granulométrica com os maiores teores de argila, e a composição do complexo sortivo na T3 e T1 possivelmente condicionam a formação de complexos organominerais mais estáveis. A presença de matéria orgânica favorece a formação de complexos organominerais de elevada estabilidade na superfície, com reflexos na estrutura do solo, pela formação de agregados bem desenvolvidos (MAJZIK; TOMBÁCZ, 2007ab).

Somado ao efeito do material de origem, os solos localizados em relevo plano e no topo (T3P1) e na várzea (T1P5) apresentaram os máximos teores de $\mathrm{C}$ org. $\mathrm{O}$ relevo plano e a posição de topo representam condições que possivelmente minimizam os efeitos da remoção de solo por erosão, enquanto que na várzea a condição de hidromorfismo é fator limitante da decomposição e mineralização da MOS. No entanto, a cobertura vegetal diferenciada da T2 com presença de leguminosas e capoeira conduz a uma situação de maior aporte de material orgânico diferenciado, que de certa forma tampona os efeitos dos demais fatores.

Costa et al. (2009) argumentam que, para situações em que há a mesma produção e deposição de biomassa vegetal no solo, o teor de matéria orgânica pode variar de solo para solo, tendo em vista a qualidade do material aportado e a influência de diversos fatores sobre a microbiota e sobre a taxa de decomposição e mineralização da matéria orgânica.

O material de origem e o relevo (posição na paisagem, drenagem e forma da superfície) determinaram a atuação e a intensidade dos processos pedogenéticos bem como as diferenças entre os atributos dos solos. Quanto aos processos, pode-se destacar a erosão no terço médio e inferior, removendo material de solo e reduzindo o teor de carbono. Outro efeito associado aos anteriores é a remoção seletiva de argila, tornando o horizonte superficial mais arenoso e reduzindo a formação de agregados estáveis, o que favorece ainda mais a erosão do solo e a decomposição da MOS (SILVA et al., 2001).

A influência do material de origem e do relevo na acumulação de matéria orgânica foi observada por Silva et al. (2007) ao longo de uma topossequência formada a partir de rocha ácida (gnaisse) e localizada em relevo montanhoso. Os autores observaram maiores teores de $\mathrm{C}$ org nos horizontes superficiais dos perfis de solo situados no topo e no terço superior da encosta em comparação aos perfis localizados no terço médio e no sopé da encosta. Silva et al. (2001) em estudo de topossequência na várzea Fluminense com rocha ácida (gnaisse e sedimentos derivados) e relevo que varia de suave ondulado a ondulado e formato de colinas (meia laranja), observaram maiores teores de $\mathrm{C}$ org na várzea (originado de sedimentos coluvio-aluvionares) com ambiente de hidromorfismo, seguido dos perfis do terço superior e com os menores teores nos terços médio e inferior.

A distribuição das frações húmicas ao longo das topolitossequências apresenta o mesmo padrão observado para o C org (Tabela 3). Dentre as frações húmicas, verifica-se o predomínio do C-HUM em todos os perfis das três topolitossequências, seguido do C-FAF na maioria dos horizontes da T1. Enquanto na T2 e T3 o C-HUM é seguido pelo C-FAF e C-FAH, ambas com teores equitativos. Na T2 e T3 observa-se o predomínio do C-FAH nos perfis localizados no topo e terço superior e o C-FAF no terço médio, terço inferior e várzea, como observado pelos valores da relação FAH/FAF (Tabela 3).

O predomínio da fração humina pode ser observado pelos baixos valores da relação EA/HUM, estes entre 0,3 e 0,7 , sendo na maioria inferiores a 0,5 (Tabela 3). Segundo proposta para classificação de solos em níveis taxonômicos inferiores (FONTANA et al., 2011), desenvolvida a partir de diversos trabalhos realizados no Brasil, os valores da relação EA/HUM $\leq 1,0$ são indicativos da baixa solubilidade da MOS.

Estudos mostram que em horizontes A moderado predomina o C-HUM, seguido pelo C-FAF (FONTANA et al., 2008). Já Correa et al. (2003) e Ibraimo et al. (2004) observaram o predomínio de C-HUM seguido pelo C-FAH. O predomínio de C-FAFem detrimento ao C-FAH em horizontes superficiais reflete as taxas diferenciadas de decomposição da matéria orgânica, estando este padrão relacionado, principalmente, ao aporte constante de materiais vegetais e a renovação do sistema radicular, que favorece a formação da fração ácidos fúlvicos (LABRADOR MORENO, 1996).

Em horizontes A chernozêmicos, o predomínio do C-HUM e os baixos valores da relação EA/HUM foram verificados por Ibraimo et al. (2004) e Fontana et al. (2010). O predomínio da humina nestes horizontes indica 
Tabela 3 - Teores de carbono orgânico e das frações húmicas dos horizontes superficiais nas topolitossequências

\begin{tabular}{|c|c|c|c|c|c|c|c|c|}
\hline \multirow{2}{*}{ Topo/Perfil ${ }^{(1)}$} & \multirow{2}{*}{ Horizonte } & \multirow{2}{*}{ Posição } & $\mathrm{C} \operatorname{org}^{(2)}$ & $\mathrm{C}-\mathrm{FAF}^{(3)}$ & $\mathrm{C}-\mathrm{FAH}^{(4)}$ & $\mathrm{C}-\mathrm{HUM}^{(5)}$ & \multirow{2}{*}{ FAH/FAF } & \multirow{2}{*}{$\mathrm{EA}^{(6)} / \mathrm{HUM}$} \\
\hline & & & \multicolumn{4}{|c|}{-----------------------g k kg } & & \\
\hline T1P1 & Ap & Topo & 18,9 & 3,5 & 2,5 & 11,3 & 0,7 & 0,5 \\
\hline T1P2 & Ap & Terço Superior & 18,5 & 3,8 & 0,9 & 10,9 & 0,2 & 0,4 \\
\hline $\mathrm{T} 1 \mathrm{P} 2$ & $\mathrm{AB}$ & Terço Superior & 12,7 & 3,5 & 1,2 & 8,9 & 0,3 & 0,5 \\
\hline T1P3 & Ap & Terço Médio & 21,7 & 3,9 & 2,8 & 11,2 & 0,7 & 0,6 \\
\hline $\mathrm{T} 1 \mathrm{P} 4$ & Ap & Terço Inferior & 22,1 & 3,2 & 2,3 & 14,2 & 0,7 & 0,4 \\
\hline $\mathrm{T} 1 \mathrm{P} 4$ & $\mathrm{AB}$ & Terço Inferior & 10,3 & 2,0 & 1,3 & 10,4 & 0,7 & 0,3 \\
\hline T1P5 & Ap & Várzea & 36,8 & 5,2 & 6,4 & 19,2 & 1,2 & 0,6 \\
\hline $\mathrm{T} 2 \mathrm{P} 1$ & Ap1 & Topo & 31,7 & 4,0 & 5,0 & 17,6 & 1,2 & 0,5 \\
\hline $\mathrm{T} 2 \mathrm{P} 1$ & Ap2 & Topo & 17,7 & 2,7 & 2,7 & 8,6 & 1,0 & 0,6 \\
\hline $\mathrm{T} 2 \mathrm{P} 2$ & Ap1 & Terço Superior & 19,2 & 2,3 & 2,3 & 9,0 & 1,0 & 0,5 \\
\hline $\mathrm{T} 2 \mathrm{P} 2$ & Ap2 & Terço Superior & 13,1 & 2,1 & 1,3 & 7,1 & 0,6 & 0,5 \\
\hline $\mathrm{T} 2 \mathrm{P} 3$ & Ap & Terço Médio & 14,7 & 2,3 & 2,9 & 8,3 & 1,3 & 0,6 \\
\hline $\mathrm{T} 2 \mathrm{P} 4$ & Ap & Terço Inferior & 14,0 & 2,3 & 1,5 & 8,9 & 0,7 & 0,4 \\
\hline $\mathrm{T} 2 \mathrm{P} 4$ & $\mathrm{AB}$ & Terço Inferior & 8,2 & 1,2 & 0,5 & 6,8 & 0,4 & 0,3 \\
\hline $\mathrm{T} 2 \mathrm{P} 5$ & Ap & Várzea & 17,7 & 3,1 & 3,0 & 9,1 & 0,9 & 0,7 \\
\hline $\mathrm{T} 3 \mathrm{P} 1$ & Ap1 & Topo & 40,0 & 5,2 & 6,4 & 23,4 & 1,2 & 0,5 \\
\hline T3P1 & Ap2 & Topo & 19,0 & 2,9 & 1,0 & 11,6 & 0,3 & 0,3 \\
\hline T3P2 & Ap & Terço Superior & 25,2 & 3,8 & 3,5 & 14,4 & 0,9 & 0,5 \\
\hline T3P3 & Ap & Terço Médio & 18,4 & 2,8 & 2,7 & 12,0 & 1,0 & 0,5 \\
\hline T3P4 & Ap & Terço Inferior & 14,9 & 2,2 & 2,0 & 10,4 & 0,9 & 0,4 \\
\hline
\end{tabular}

${ }^{(1)}$ Topo: topossequência; ${ }^{(2)} \mathrm{C}$ org: carbono orgânico; ${ }^{(3)} \mathrm{C}$-FAF: carbono da fração ácidos fúlvicos; ${ }^{(4)} \mathrm{C}$-FAH: carbono da fração ácidos húmicos; ${ }^{(5)} \mathrm{C}-$ HUM: carbono da fração humina; ${ }^{\left({ }^{6}\right.} \mathrm{EA}$ : C-FAF + C-FAH

a forte interação entre a matéria orgânica e a matriz mineral pela formação de complexos organominerais de elevada estabilidade na superfície do solo, deixando insolúvel a maior parte da matéria orgânica (MAJZIK; TOMBÁCZ, 2007ab).

Os baixos valores da relação EA/HUM, indicam em parte, a forte relação entre a matéria orgânica e a matriz mineral pela formação de complexos organominerais de elevada estabilidade, proporcionada pela presença de cátions trocáveis, principalmente do $\mathrm{Ca}^{2+}$. Neste sentido, diferentes ensaios com solos têm destacado o papel dos cátions trocáveis na estabilidade da estrutura e no aumento dos teores de matéria orgânica (GRÜNEWALD et al., 2006; WUDDIVIRA; CAMPS-ROACH, 2007; MAJZIK; TOMBÁCZ, 2007ab; BONINI; ALVES, 2011; VIRTO; GARTZIA-BENGOETXEA; FERNÁNDEZ-UGALDE, 2011; BRIEDS et al., 2012).
Os teores de $\mathrm{C}$ org e as frações húmicas apresentaram correlações distintas com os atributos químicos e físicos, de acordo com o tipo de material de origem (Tabelas 4, 5 e 6). Para a T1, o C org, C-FAH e C-HUM apresentaram correlação negativa com a fração argila (-0,86 a -0,97), espúria para este trabalho (Tabela 4), e positiva com a CTC $(0,88$ a 0,96$)$.

Para os solos da T2, observa-se correlação positiva do $\mathrm{C}$ org e das frações húmicas com $\mathrm{Ca}^{2+}$, $\mathrm{Mg}^{2+}$ e CTC $(0,86$ a 0,98) (Tabela 5). Para a T3, foram vertificadas correlações positivas entre o $\mathrm{C}$ org e as frações húmicas com os teores de $\mathrm{Ca}^{2+}$, e do C-FAF com a CTC $(0,89)$ (Tabela 6). Os resultados das correlações do $\mathrm{C}$ org e das frações húmicas com os componentes do complexo sortivo dos solos das três topolitossequências destaca a participação ativa da matéria orgânica na retenção de cátions destes solos. 
Tabela 4 - Correlação dos atributos com o carbono orgânico e as frações húmicas da topolitossequência de basalto (T1)

\begin{tabular}{lcccc}
\hline \multicolumn{1}{c}{ Atributos } & ${\mathrm{C} \text { org }^{(1)}}^{\prime}$ & $\mathrm{C}-\mathrm{FAF}^{(2)}$ & $\mathrm{C}-\mathrm{FAH}^{(3)}$ & $\mathrm{C}^{-\mathrm{HUM}^{(4)}}$ \\
\hline Areia Grossa & $0,91^{*}$ & $0,77^{*}$ & $0,95^{*}$ & $0,93^{*}$ \\
Areia Fina & $0,88^{*}$ & 0,67 & $0,83^{*}$ & $0,93^{*}$ \\
Silte & 0,56 & 0,19 & 0,67 & $0,80^{*}$ \\
Argila & $-0,86^{*}$ & $-0,58$ & $-0,90^{*}$ & $-0,97^{*}$ \\
$\mathrm{pH}$ (água) & $-0,20$ & $-0,64$ & $-0,10$ & 0,10 \\
$\mathrm{Ca}^{2+}$ & 0,26 & $-0,22$ & 0,35 & 0,57 \\
$\mathrm{Mg}^{2+}$ & $-0,16$ & $-0,45$ & $-0,19$ & $-0,09$ \\
$\mathrm{Al}^{3+}$ & $-0,44$ & 0,03 & $-0,5$ & $-0,60$ \\
$\mathrm{CTC}^{(5)}$ & $0,88^{*}$ & 0,61 & $0,94 *$ & $0,96^{*}$ \\
\hline
\end{tabular}

${ }^{(1)} \mathrm{C}$ org: carbono orgânico; ${ }^{(2)} \mathrm{C}-\mathrm{FAF}$ : carbono da fração ácidos fúlvicos; ${ }^{\left({ }^{3}\right)} \mathrm{C}-\mathrm{FAH}$ : carbono da fração ácidos húmicos; ${ }^{(4)} \mathrm{C}-\mathrm{HUM}$ : carbono da humina; ${ }^{(5)} \mathrm{CTC}$ : capacidade de troca catiônica a pH 7,0; *Significativo a $\alpha=0,05$

Tabela 5 - Correlação dos atributos com o carbono orgânico e as frações húmicas da topolitossequência de muscovita-biotina-gnaisse (T2)

\begin{tabular}{lllll}
\hline Atributos & $\mathrm{C}$ org $^{(1)}$ & $\mathrm{C}-\mathrm{FAF}^{(2)}$ & $\mathrm{C}-\mathrm{FAH}^{(3)}$ & $\mathrm{C}-\mathrm{HUM}^{(4)}$ \\
\hline Areia Grossa & $-0,40$ & $-0,27$ & $-0,35$ & $-0,56$ \\
Areia Fina & $-0,03$ & $-0,09$ & $-0,16$ & 0,24 \\
Silte & 0,53 & 0,52 & 0,54 & 0,55 \\
Argila & 0,21 & 0,12 & 0,28 & 0,08 \\
$\mathrm{pH}$ (água) & 0,62 & 0,64 & 0,55 & 0,68 \\
$\mathrm{Ca}^{2+}$ & $0,95^{*}$ & $0,91^{*}$ & $0,86^{*}$ & $0,97^{*}$ \\
$\mathrm{Mg}^{2+}$ & $0,91^{*}$ & $0,88^{*}$ & $0,86^{*}$ & $0,94^{*}$ \\
$\mathrm{Al}^{3+}$ & $-0,58$ & $-0,69$ & $-0,63$ & $-0,39$ \\
$\mathrm{CTC}^{(5)}$ & $0,98^{*}$ & $0,97^{*}$ & $0,96^{*}$ & $0,96^{*}$ \\
\hline
\end{tabular}

${ }^{(1)} \mathrm{C}$ org: carbono orgânico; ${ }^{(2)} \mathrm{C}-\mathrm{FAF}$ : carbono da fração ácidos fúlvicos; ${ }^{(3)} \mathrm{C}-\mathrm{FAH}$ : carbono da fração ácidos húmicos; ${ }^{(4)} \mathrm{C}-\mathrm{HUM}$ : carbono da humina; ${ }^{(5)}$ CTC: capacidade de troca catiônica a $\mathrm{pH} 7,0 ; *$ Significativo a $\alpha=0,05$

Tabela 6 - Correlação dos atributos com o carbono orgânico e as frações húmicas da topolitossequência de gabro (T3)

\begin{tabular}{lcccc}
\hline \multicolumn{1}{c}{ Atributos } & ${\mathrm{C} \text { org }^{(1)}}^{\prime}$ & $\mathrm{C}-\mathrm{FAF}^{(2)}$ & $\mathrm{C}-\mathrm{FAH}^{(3)}$ & $\mathrm{C}^{-\mathrm{HUM}^{(4)}}$ \\
\hline Areia Grossa & $-0,56$ & $-0,51$ & $-0,78$ & $-0,62$ \\
Areia Fina & $-0,32$ & $-0,32$ & 0,03 & $-0,28$ \\
Silte & 0,26 & 0,16 & 0,25 & 0,32 \\
Argila & 0,68 & 0,68 & 0,52 & 0,68 \\
$\mathrm{pH}$ (água) & $-0,63$ & $-0,73$ & $-0,52$ & $-0,55$ \\
$\mathrm{Ca}^{2+}$ & $0,95^{*}$ & $0,95^{*}$ & 0,79 & $0,93^{*}$ \\
$\mathrm{Mg}^{2+}$ & 0,68 & 0,70 & 0,37 & 0,63 \\
$\mathrm{Al}^{3+}$ & - & - & - & - \\
$\mathrm{CTC}^{(5)}$ & 0,86 & $0,89^{*}$ & 0,64 & 0,82 \\
\hline
\end{tabular}

${ }^{(1)} \mathrm{C}$ org: carbono orgânico; ${ }^{(2)} \mathrm{C}-\mathrm{FAF}$ : carbono da fração ácidos fúlvicos; ${ }^{\left({ }^{3}\right)} \mathrm{C}-\mathrm{FAH}$ : carbono da fração ácidos húmicos; ${ }^{\left({ }^{4}\right)} \mathrm{C}-\mathrm{HUM}$ : carbono da humina; ${ }^{(5)} \mathrm{CTC}$ : capacidade de troca catiônica a $\mathrm{pH} 7,0 ; *$ Significativo a $\alpha=0,05$ 


\section{CONCLUSÕES}

1. Os teores de carbono orgânico variaram de acordo com o material de origem obedecendo a seguinte sequência: T3 ( gabro) > T1 (basalto) > T2 (muscovita-biotita-gnaisse);

2. Os teores de carbono orgânico aumentaram do topo para a várzea na $\mathrm{T} 1$, ocorrendo o inverso na $\mathrm{T} 3$ e sem um padrão definido na T2;

3. A fração humina predominou em todos os perfis de solo das três topolitossequências, sendo seguida pela fração ácidos fúlvicos na $\mathrm{T} 1 \mathrm{e}$ de forma equitativa entre as frações ácidos fúlvicos e ácidos húmicos na T2 e T3.

\section{AGRADECIMENTOS}

À Coordenação de Aperfeiçoamento de Pessoal de Nível Superior/CAPES pela bolsa de estudo, ao Conselho Nacional de Desenvolvimento Científico e Tecnológico/CNPq pelo suporte ao projeto de pesquisa e ao Instituto Federal de Educação, Ciência e Tecnologia do Rio de Janeiro, Campus Pinheiral, pelo suporte na coleta das amostras de solo.

\section{REFERÊNCIAS}

BENITES, V. M. MADARI, B.; MACHADO, P. L. O. A. Extração e fracionamento quantitativo de substâncias húmicas do solo: um procedimento simplificado de baixo custo. Rio de Janeiro: Embrapa Solos, Comunicado Técnico, 16, 2003. 7 p.

BONINI; C. S. B.; ALVES, M. C. Estabilidade de agregados de um Latossolo Vermelho degradado em recuperação com adubos verdes, calcário e gesso. Revista Brasileira de Botânica, v. 35, n. 4, p. 1263-1270, 2011.

BRASIL. Geologia, geomorfologia, pedologia, vegetação e uso potencial da terra. Projeto Radam Brasil Folhas SF, 23/24. Rio de Janeiro/Vitória: Rio de Janeiro: IBGE/Ministério das minas e energia - Secretaria Geral, 1983. v. 32. (Levantamento de Recursos Naturais).

BRIEDIS, C. et al. Soil organic matter pools and carbon-protection mechanisms in aggregate classes influenced by surface liming in a no-till system. Geoderma, v. 170, n. 1, p. 80-88, 2012.

COSTA, O. V. et al. Estoque de carbono do solo sob pastagem em área de tabuleiro costeiro no sul da Bahia. Revista Brasileira de Ciência do Solo, v. 33, n. 5, p. 1137-1145, 2009.

CORRÊA, M. M. etal. Atributos físicos, químicos e mineralógicos de solos da região de várzeas de Souza (PB). Revista Brasileira de Ciência do Solo, v. 27, n. 2, p. 311-324, 2003.

EMBRAPA. Manual de métodos de análise de solos. Rio de Janeiro, 1997. $212 \mathrm{p}$.

EMBRAPA. Sistema brasileiro de classificação de solos. 2. ed. Rio de Janeiro: Embrapa Solos, 2006, 306 p.
FONTANA, A. et al. Substâncias húmicas como suporte à classificação de solos Brasileiros. Revista Brasileira de Ciência do Solo, v. 32, n. 5, p. 2073-2080, 2008.

FONTANA, A. et al. Quantificação e utilização das frações húmicas como característica diferencial em horizontes diagnósticos de solos brasileiros. Revista Brasileira de Ciência do Solo, v. 34, n. 4, p. 1241-1247, 2010.

FONTANA, A. et al. Proposta de classificação de horizontes diagnósticos minerais em níveis hierárquicos inferiores com base nas frações húmicas. Rio de Janeiro: Embrapa Solos, Boletim de Pesquisa e Desenvolvimento, 192, 2011, 26 p.

GREENLAND, D. J.; WILD, A.; ADAMS, D. Organic matter dynamics in soils of the tropics - from myth to complex reality. In: LAL, R.; SANCHEZ, P. A. Myths and science of soils of the tropics. SSSA, Special Publication n.29. Wisconsin: Copyright, 1992. p. 17-33.

GRÜNEWALD, G. et al. Organic matter stabilization in young calcareous soils as revealed by density fractionation and analysis of lignin-derived constitution. Organic Geochemistry, v. 37, n. 11, p. 1573-1589, 2006.

IBRAIMO, M. M. et al. Gênese e micromorfologia de solos sob vegetação xeromórfica (caatinga) na região dos lagos (RJ). Revista Brasileira de Ciência do Solo, v. 28, n. 3, p. 695-712, 2004.

LABRADOR MORENO, J. La matéria orgânica em los agrosistemas. Madrid: Ministerio de Agricultura Pesca y Alimentación, 1996. 174 p.

LEITE, L. F. C. et al. Estoques totais de carbono orgânico e seus compartimentos em Argissolo sob floresta e sob milho cultivado com adubação mineral e orgânica. Revista Brasileira de Ciência do Solo, v. 27, n. 5, p. 821-832, 2003.

MAJZIK, A.; TOMBÁCZ, E. Interaction between humic acid and montmorillonite in the presence of calcium ions I. Interfacial and aqueous phase equilibria: Adsorption and complexation. Organic Geochemistry, v. 38, n. 8, p. 1319-1329, 2007 a.

MAJZIK, A.; TOMBÁCZ, E. Interaction between humic acid and montmorillonite in the presence of calcium ions II. Colloidal interactions: Charge state, dispersing and/or aggregation of particles in suspension. Organic Geochemistry, v. 38, n. 8, p. 1330-1340, 2007b.

MIELNICZUK, J. et al. Manejo de solo e culturas e sua relação com os estoques de carbono e nitrogênio do solo. In: CURI, N. et al. Tópicos em ciência do solo. Viçosa: SBCS, 2003, v. 3, p. 209-248.

PEREIRA, M. G. et al. Caracterização e classificação de solos em uma topossequência sobre calcário na Serra da Bodoquena, MS. Revista Brasileira de Ciência do Solo, v. 37, n. 1, p. 25-36, 2013.

SANTOS, R. D. et al. Manual de descrição e coleta de solo no campo. 5. ed. Viçosa, SBCS/EMBRAPA/CNPS, 2005. 100 p.

SANTOS, A. C. Pedogênese e alterações geoquímicas em topolitossequências na Bacia do Ribeirão do Cachimbal na Região do Médio Vale do Paraíba, RJ. 2009. 268 f. Tese (Doutorado em Agronomia - Ciência do Solo) - Universidade Federal Rural do Rio de Janeiro, Seropédica, 2009. 
SILVA, M. B. et al. Estudo de topossequência da várzea litorânea fluminense: efeitos do material de origem e posição topográfica. Revista Brasileira de Ciência do Solo, v. 25, n. 5, p. 965-976, 2001.

SILVA, A. C. et al. Relações entre matéria orgânica do solo e declividade de vertentes em topossequencia de Latossolos do sul de Minas Gerais. Revista Brasileira de Ciência do Solo, v. 31, n. 5, p. 1059-1068, 2007.

SOUZA, E. D. et al. Frações do carbono orgânico, biomassa e atividade microbiana em um Latossolo Vermelho sob cerrado submetido a diferentes sistemas de manejos e usos do solo. Acta Scientiarum. Agronomy, v. 28, n. 3, p. 323-329, 2006.

TORNQUIST, C. G. et al. Soil organic carbon stocks of Rio Grande do Sul, Brazil. Soil Science Society of America Journal, v. 73 , n. 3, p. $975-982,2009$.
VIRTO, I.; GARTZIA-BENGOETXEA, N.; FERNÁNDEZUGALDE, O. Role of organic matter and carbonates in soil aggregation estimated using laser diffractometry. Pedosphere, v. 21, n. 5, p. 566-572, 2011.

WANDER, M. M. Soil organic matter fractions and their relevance to soil function. In: MAGDOFF, F.; WEIL, R. Advances in Agroecology, CRC Press LLC, 2004. p. 67-102.

WUDDIVIRA, M. N.; CAMPS-ROACH, G. Effects of organic matter and calcium on soil structural stability. European Journal of Soil Science, v. 58, n. 3, p. 722-727, 2007.

YEOMANS, J. C.; BREMNER, J. M. A rapid and precise method for routine determination of organic carbon in soil. Soil Science and Plant Analysis, v.19, n. 13, p. 1467-1476, 1988. 